\title{
Exploring the Transaction Dimensions of Supply Chain Management
}

\author{
Britta Lietke and Madlen Boslau ${ }^{1}$ \\ Georg-August-Universitaet Goettingen, Institute for Marketing and Retailing, \\ Nikolausberger Weg 23, 37073 Goettingen, Germany \\ \{blietke, mboslau\}@uni-goettingen.de
}

\begin{abstract}
It is argued that firm cooperation in supply chain management can be classified as a hybrid governance structure in a new institutional sense. Using a key informant survey, exploratory data on transaction dimensions and supply chain management was gathered and analyzed. Findings suggest that the implementation of such cooperation is not a binary choice but rather a matter of varying degrees. All factors commonly associated with influencing transaction costs (asset specificity, uncertainty and frequency) are significantly higher for firms with more fully implemented supply chain management, making a more integrated solution advantageous. Additionally, the data suggests a strong influence of transaction frequency on the degree of asset specificity and uncertainty.
\end{abstract}

\section{Introduction and Problem Delimitation}

Using the market for economic transactions always entails costs. These transaction costs are present in addition to regular production costs and arise when creating, assigning, transferring or implementing property rights. They may include information and communication costs, as well as time and effort employed when managing exchanges. Due to these costs, it is more efficient in some instances to choose a hierarchical governance structure instead of using open market transactions. This is the case when the governance costs for a market transaction are particularly high, as the transaction is likely to be able to be conducted at lower cost in a hierarchy.

When transaction costs lie somewhere between these two extremes hybrid governance forms are often sought as a solution. "The term hybrid does not refer to a distinct category of organizational forms but to a diverse collection of relationships that either combine contracting and vertical integration or lie somewhere between markets and

\footnotetext{
${ }^{1}$ The authors wish to express their gratitude to the participants of the project seminar "Value Added Networks" for their effort in conducting the telephone survey, the members of the IMH for their support, as well as Judit Simon and the conference participants of EMNet 2005 for the helpful feedback.
} 
hierarchies in terms of incentive intensity, adaptability, and bureaucratic costs" [1]. Organizational structures such as joint ventures, strategic alliances or franchising as well as other networks can be considered hybrid.

With this understanding, cooperation of firms in the form of supply chain management (SCM) can also be classified as hybrid forms of governance in a new institutional sense. A "systemic, strategic coordination [...] across businesses" [2] is both long-term and hierarchical in structure, thus differing from an arm's-length market transaction. The fact that the businesses remain independent economic entities, however, indicates market features.

According to this reasoning, a first exploratory empirical examination of the factors causing transaction costs to occur in SCM should show that they vary with the degree of SCM implementation. More specifically, we argue that, the more thoroughly SCM is implemented and carried out between firms, the higher the corresponding transaction dimensions asset specificity, uncertainty and frequency are. To test this hypothesis, a phone and email based survey was conducted at the Institute for Marketing and Retailing in Göttingen, Germany investigating this relationship based on the three dimensions first proposed by Williamson [3], [4]. Key informants are interviewed with respect to both frequency and uncertainty of transactions within SCM as well as the specificity of the investments undertaken for SCM implementation (see [5], [6], or [7] for similar approaches).

This article reports on first study results and their consequences for both economics and management. Questions which will be answered include: Is SCM another hybrid form as suggested by transaction cost economics? Does the degree of implementation of SCM, i.e. the strength of cooperative efforts imply greater values for the factors causing transaction internalization? How important are the dimensions of the transactions for members of a supply chain when choosing to implement SCM? Can firms decide on whether implementation of SCM is feasible or not based on the costs of their relevant transactions?

\section{Supply Chain Management}

In order to be able to analyze organizational structures within a transaction cost framework and test predictions empirically, it is necessary to precisely describe and define the institutional arrangement of cooperation called supply chain management. Mentzer et al. [2] point out that considerable confusion exists as to the meaning of SCM both in academia and practice. It has been defined as anything from purely operational (see e.g. [8]), involving logistics flows of products and information, to a management philosophy (see e.g. [9]) or a management process (see e.g. [10]). A reason for this variety of definitions may be the fact that, in practice, many different degrees of supply chain management practice are found, all of which are subsumed under the same term but may in fact differ substantially.

Clearly, SCM as "the systemic, strategic coordination of the traditional business functions and the tactics across these business functions within a particular company and across businesses in a supply chain, for the purposes of improving the long-term performance of the individual companies and the supply chain as a whole" as the 
definition provided by Mentzer et al. [2] reads, is hardly found among businesses in reality. More realistically, such a definition is the ultimate goal of effective and efficient cooperation between companies. So far, all attempts among firms to cooperate with each other through SCM are at best partial implementations of this definition. Depending on the degree of cooperation, SCM is implemented more or less strongly.

These varying degrees of implementation may be attributed to different levels of what Mentzer et al. [2] term "supply chain orientation", the overall recognition of the strategic and systemic impact of activities which manage supply chain flows. Likewise, firms implementing SCM cooperation ought to fulfill certain prerequisites such as trust, commitment and interdependence, for example. As with supply chain orientation, the degree of fulfilling the conditions for an intensive SCM implementation may vary substantially across firms and may, hence, enhance or impede fully cooperative SCM.

Depending on the specific endowments of the firm and relevant partners, different costs arise with the implementation of SCM. Here, not only one-time investments in SCM software or employee trainings are meant, but all costs, both de facto and opportunity costs, that incur with implementing some level of SCM. Transaction Cost Economics provides a framework to analyze costs incurred due to a certain choice of governance structure. As SCM is one possible organizational alternative, the next section will place it into a transaction costs perspective.

\section{Transaction Cost Analysis of Supply Chain Management}

From a transaction cost point-of-view, a full implementation of SCM across all supply chain members represents the form of cooperation closest to vertical integration. Some authors refer to this as quasi (-vertical) integration (see e.g. [11], [12], [13]). The less fully SCM is implemented, the more market-like are the transactions which take place. Hence, different degrees of SCM implementation ought to yield differences in the levels of attributes causing transaction costs.

Williamson [3] names three principal factors which cause transaction costs to arise. The greater their impact, the less efficient is market-based transacting. Next, each of them will be considered in relation to SCM. Testable propositions will be presented in turn.

\subsection{Asset Specificity}

Asset specificity describes how well an asset may be redeployed in its second-best use. The more specific an asset, the less is its value in alternative uses by alternative users [3], [14]. Hence, the more specific an asset, the stronger the dependency on its first-best use and the more severe are the contracting hazards. As a result, more integrative solutions will be sought to carry out those transactions which largely depend on specific assets. Assets specific to SCM cooperation may include, but are not limited to, investments in SCM software or hardware for information exchange such as EDI, specifically trained employees and managers working in the supply 
chain management department, or the cost incurred from running such a department. In addition to these pecuniary costs that the company has to bear, there are opportunity costs that need to be considered when quantifying the true economic cost of the specific investment in SCM. When the chosen governance structure is not the first best solution for managing the transaction, the total costs of this coordination format will be higher than the total benefits, resulting in a net loss. These costs are sometimes referred to as misalignment costs [15]. In the specific case of SCM, misalignment costs incur when a firm has implemented SCM to the wrong extent i.e. has made a type 1 or type 2 organizational error by either choosing a too integrated or too market-oriented form of SCM cooperation.

As a general tendency, however, we can state that the higher the specific investments in assets relevant to SCM are, the more integrated should be the respective governance structure, as firms attempt to prevent post-contractual opportunistic behavior aimed at extracting quasi-rents. In the case of supply chain management, one should in this case observe a more complete, i.e. more intensively cooperative, implementation as formulated in the first proposition.

Proposition 1: When observing a stronger implementation of SCM the corresponding level of asset specificity should be higher as well.

\subsection{Uncertainty}

When a transaction is highly uncertain, a market transaction is unlikely to provide adequate control mechanisms to sufficiently govern this transaction. Opportunistic behavior is likely and difficult to prevent when some aspects of the transaction are highly uncertain. Ceteris paribus, very little uncertainty surrounding a transaction makes markets more feasible [11].

Uncertainty in SCM can occur in various forms. Firms may be uncertain how well trading partners will meet their contractual performance agreements. Also, unforeseen changes in the environment such as varying prices of inputs or demand for output influence the relations to buyers and suppliers. Size of order or the time between orders may vary accordingly. These examples of uncertainty are commonly subsumed under external uncertainty, i.e. the uncertainty generated by firms being unable to anticipate or predict changes a volatile environment [16].

Another form of uncertainty is internal to the coordination structure and results when firms are unable to assess their own future performance. This also includes behavioral uncertainty resulting from the possibility that informational asymmetries will be opportunistically exploited by one of the trading partners.

In order to better contain both forms of uncertainty there is a need to more accurately and intensively control, coordinate and monitor the transactions themselves, the behavior of the other parties involved in the transaction and environmental changes. As this becomes more difficult to accomplish for arm's-length market transactions, more integrative solutions will be sought [7]. Hence, the degree of integration should increase with the difficulty of monitoring performance and we can formulate the following assumption with respect to SCM intensity. 
Proposition 2: Closer cooperation, i.e. a stronger implementation of SCM should correlate with higher levels of uncertainty.

In addition to making market transactions be completed less smoothly than in more certain environments, greater uncertainty causes specific investments to be even riskier. Such investments are better protected under a more integrative governance structure. Similarly, adaptations to transactions due to unforeseen changes are more easily carried out when the governance mechanism is more strongly vertically integrated, as no formal contracts are to be revised [16], [7]. Therefore, the effects of asset specificity become more severe in more uncertain settings, yielding the next hypothesis.

Proposition 3: Higher levels of uncertainty amplify the impact of asset specificity as an influencing factor on transaction costs.

\subsection{Frequency}

Of the three attributes influencing transaction costs, frequency is the least straightforward in its influence. Frequency describes how often and how regularly a certain type of transaction is repeated. Its influence on transaction costs has been discussed somewhat controversially in the literature (see e.g. [17], [11]). It seems that, depending on the particular circumstances, frequency can cause transactions to be more of an arm's-length character as well as more integrated, as illustrated in the following lines of argument.

Hobbs [11] argues that, if standard transactions are repeated frequently between two parties, both have an incentive to not behave opportunistically as otherwise future profits from the repeat business will be forgone. Furthermore, repeated transactions are a means to gather information about the other party. As a result, a lower degree of information asymmetry is present and therefore transactions are best carried out in the market. However, once parties transact more infrequently, incentives to act opportunistically and exploit information asymmetries for a large one-off advantage increase. To avoid such opportunism, transactions will be carried out in a more integrated governance form.

On the other hand, Williamson [17] reasons that, with an increasing frequency of transacting, opportunity costs arise under a market structure due to foregone efficiencies of the economies of scale of vertical coordination. However, this line of argument assumes a high degree of asset specificity and/or uncertainty for scale economies to arise as only then it is sensible to implement controls and monitoring systems which pay off more quickly as frequency rises.

So far, it has not been satisfactorily shown which of these two assumptions holds or whether both could be consistent with each other. A significant relationship between frequency and the degree of vertical integration could not be verified empirically in most transaction cost studies. Furthermore, many studies do not take frequency into account due to the somewhat problematic assessment of its influence (see e.g. [18] or [19]). 
Resulting from this deficit, two hypotheses concerning the frequency of transactions will be postulated. First, we follow Williamson's original argument by proposing that frequency impacts existing levels of asset specificity and uncertainty in our next proposition.

Proposition 4: Higher levels of frequency amplify the impact of both asset specificity and uncertainty as influencing factors on transaction costs.

Second, we assume that frequency of transactions does constitute an additional dimension of transaction cost influencing factors. Hence, frequency can lead to potential economies of scale which are most beneficial at a high degree of quasiintegration (that is, fully implemented SCM) as stated in the following hypothesis.

Proposition 5: When observing closer cooperation through a stronger implementation of SCM, higher levels of frequency should be present as well.

While literature generally supports the tendencies in which the three dimensions discussed here influence transaction costs of market exchanges and hence support choices of hybrid or fully integrated governance structures when costs are high, to our knowledge no prior empirical research as examined the transaction costs incurred by formal SCM. Therefore, a survey was conducted to gather data on the characteristics of the transaction dimensions observed in SCM.

\section{Empirical Tests of Propositions}

The above hypotheses were tested on survey data from companies which explicitly manage their supply chains. This section will introduce the general research procedure, describe the sample and discuss the empirical assessment of the above propositions by operationalizing SCM and the dimensions of the transactions.

\subsection{General Research Procedure}

To test the predictions of transaction cost theory, the dependent variable SCM implementation needs to be operationalized. As transaction cost economics predict more integrated governance structures with increasing levels of asset specificity, uncertainty and frequency, it is necessary to find measures indicating the degree to which one firm's supply chain management is more vertically integrated than another's. A number of questions were used to measure the degree to which the questioned companies implemented SCM. More specifically, we tried to assess not only the formal criteria for an SCM implementation like software usage, or the importance of SCM within the company and the success of implementation, but also the factors more indicative of a "real" supply chain orientation as defined by Mentzer et al. [2]. Thus, questions also measured the questioned firm's trust in its SCM partners, the level and ease of communication between them and the ability to react to changes when requested by one of the cooperating SCM partners. 
Using these estimators, we intend to group the sample into groups according to their degree of formal SCM implementation which will then be compared with respect to the dimensions of the transaction. To do this, these dimensions were operationalized using multiple questions derived from previous TCE survey questions (see [5], [6], [7], [18]) which we adjusted to fit the SCM problem formulation. Using principal component analysis, the questions were condensed to form single factors measuring asset specificity, uncertainty and frequency. The variations in these dimensions are then analyzed for the different groups of companies. Additionally, the relationships between these dimensions and possible influences are analyzed.

\subsection{Sample}

The sample was drawn from lists of companies known for practicing SCM which were available online. Used sources of information include SAP case studies ${ }^{2}$, www.logistik-inside.de, a German forum for logistics specialists and returns from our own subsequent internet research. Only the contact details of those companies were collected where evidence suggested at least a certain involvement in the management of the supply chain, i.e. more efforts than traditional logistics. A list of more than 150 companies was created and they were contacted between March and May 2005. Of those, 35 companies agreed to participate in the survey, yielding an overall response rate of approximately $23 \%$.

Table 1. Sample Characteristics $(n=35)$

\begin{tabular}{|c|c|c|c|c|c|c|c|c|c|}
\hline \multicolumn{4}{|c|}{ Manufacturers } & \multicolumn{2}{|c|}{ Retailers } & \multicolumn{4}{|c|}{ Service Providers } \\
\hline \multicolumn{4}{|c|}{32} & \multicolumn{2}{|l|}{2} & \multicolumn{4}{|c|}{1} \\
\hline \multicolumn{10}{|c|}{ Industry of Respondent Company } \\
\hline \multicolumn{2}{|c|}{ Automobile } & \multicolumn{2}{|c|}{ Chemicals } & M. Engineering & Construction & Food & Paper & Metal & Other \\
\hline \multicolumn{2}{|r|}{13} & \multicolumn{2}{|c|}{7} & 5 & 3 & 2 & 2 & 1 & 2 \\
\hline \multicolumn{10}{|c|}{ Number of Employees } \\
\hline$<100$ & \multicolumn{2}{|c|}{ 100-199 } & $\begin{array}{c}200- \\
499 \\
\end{array}$ & $500-999$ & \multicolumn{2}{|c|}{$1000-5000$} & \multicolumn{2}{|c|}{$>5000$} & n.s. \\
\hline 3 & \multicolumn{2}{|c|}{0} & 6 & 4 & \multicolumn{2}{|l|}{11} & \multicolumn{2}{|c|}{8} & 3 \\
\hline \multicolumn{10}{|c|}{ Number of Employees in Supply Chain Management } \\
\hline$<100$ & \multicolumn{2}{|c|}{$100-199$} & $\begin{array}{r}200- \\
499 \\
\end{array}$ & $500-999$ & \multicolumn{2}{|c|}{$1000-5000$} & \multicolumn{2}{|c|}{$>5000$} & n.s. \\
\hline 4 & \multicolumn{2}{|c|}{3} & 7 & 3 & \multicolumn{2}{|l|}{2} & \multicolumn{2}{|c|}{2} & 14 \\
\hline \multicolumn{10}{|c|}{ Department of Respondent } \\
\hline SCM & Logistics & \multicolumn{2}{|c|}{$\begin{array}{c}\text { Executive } \\
\text { Management }\end{array}$} & Marketing/Sales & Purchasin & \multicolumn{2}{|c|}{ Controlling } & Other & n.s. \\
\hline 10 & 9 & \multicolumn{2}{|c|}{3} & 3 & 2 & & 2 & 3 & 3 \\
\hline
\end{tabular}

\footnotetext{
${ }^{2}$ SAP offers software especially designed to manage supply chains, known as mySAP SCM which is part of the mySAP Business Suite [20].
} 
An examination of the sample characteristics (table 1) shows a clear bias towards manufacturers as opposed to retailers or service providers. Industry-wise, as well as with respect to company size, the sample reveals substantial variations. However, despite the diversity and variance among firms in the sample, we stress the fact that it is non-random in nature. As we intentionally chose only those firms known for having implemented some kind of formal SCM, the lists used may contain biases of unknown magnitude. Thus, further studies may be necessary to validate results based on a more random sample.

\subsection{Method}

As the study concerns itself with organizational-level variables, it seemed sensible to question key informants in the respective firms using a standardized format questionnaire to gather the data through telephone interviews. Such key informant surveys have proven to provide reliable and valid data on the structural form of intercompany relationships in earlier studies [21], [22]. Our deliberate selection of individuals which are knowledgeable about the exact nature of their organization's SCM seems reasonable.

The majority of informants in this survey were SCM managers (see Table 1). This choice is justified on the grounds that individuals supervising the SCM department are most knowledgeable on their company's specific form of SCM implementation. In companies with no SCM department, a manager responsible for managing supplier and buyer relations was chosen. These managers came mostly from the logistics department or the executive board (see Table 1). These choices are also reasonable as individual companies may not name the relevant department according to our definition of SCM but may in fact practice SCM as their role definition for the logistics department includes close cooperation with their supply and demand relations. Whether this was the case for the individual firm was ascertained by the interviewer prior to conducting the interview by asking the respondent to specify the role of the department concerned and the firm's understanding of SCM.

The standardized survey was conducted via telephone interviews usually lasting 10 to 15 minutes. Questions operationalizing SCM and the three transactional dimensions were all formulated on a 5-point Likert scale ranging from $1=$ "not at all" to $5=$ "a lot". All interviewers, before beginning with the interview, explained to the interviewees their role as informants as opposed to respondents in the sense of test persons and asked them for an as objective as possible answer. Also, our understanding of SCM as a cooperative governance form to coordinate exchanges rather than a new name for logistics management was explained prior to conducting the interview.

\subsection{Measures}

Two groups of measures are central to the testing of the derived hypotheses. The degree of SCM implementation is needed to cluster the firms into groups to then analyze these groups for differences in the transaction dimensions. These dimensions 
need to be aggregated using factor analysis. The procedures used will be presented in more detail in the following.

\subsubsection{Degree of SCM Implementation}

As discussed in section 4.1 the dependent variable of SCM implementation was measured through a number of questions derived from the characteristics stated in the literature on formal SCM implementation and practice. Mentzer et al. [2] name a number of SCM activities commonly deemed necessary for 'proper' supply chain management. Using the questions designed to measure the extent of these activities as estimators, we cluster the respondents into two groups according to their degree of formal SCM implementation.

Cluster analysis seems feasible as this set of multivariate tools is commonly used for building groups (clusters) from multivariate data objects. Cluster analyses aim to create groups with homogeneous properties within the respective group out of large heterogeneous samples. The clusters obtained should be as homogeneous as possible and the differences among the various groups as large as possible. With the limited size of the sample, it is necessary to confine the resulting number of clusters to a minimum, while still obtaining as homogenous a group as possible. Therefore, we chose the Ward clustering algorithm as this procedure unifies groups such that variation inside the groups does not increase too severely and resulting groups are as homogeneous as possible. It does this, in contrast to linkage procedures, not by putting together groups with smallest distances but instead by joining groups such that a given measure of heterogeneity does not increase 'too much' [23].

Figure 1 shows the resulting dendrogram when using Ward's Method for grouping. It is clearly observable that the sample does consist of two quite dissimilar groups, cluster $1(\mathrm{~N}=16)$ and cluster $2(\mathrm{~N}=19)$. A comparison of the mean values for all SCM implementation variables between the two clusters indicates which characteristics are mainly responsible for differences in the clusters. As the results in table 2 indicate, the means in cluster 2 are higher for all but one item. The difference in means for SCM software usage between the two groups is most significant ( $99 \%$ confidence), but also the level of trust in cooperation partners is a highly significant (95\% confidence) differentiator between the two clusters. As a general result, this analysis shows that cluster 2 is made up of those firms who have implemented SCM to a greater extent. Cluster 1 firms tend to score lower for almost all SCM activity indicators. This implies that the extent to which those firms have implemented activities central to effective SCM is comparatively lower, indicating a less integrated solution. ${ }^{3}$

\footnotetext{
3 These results were further confirmed by an additional discriminant analysis yielding an excellent Wilks' Lambda of $.113(\mathrm{p}=.000)$.
} 
10 Britta Lietke and Madlen Boslau

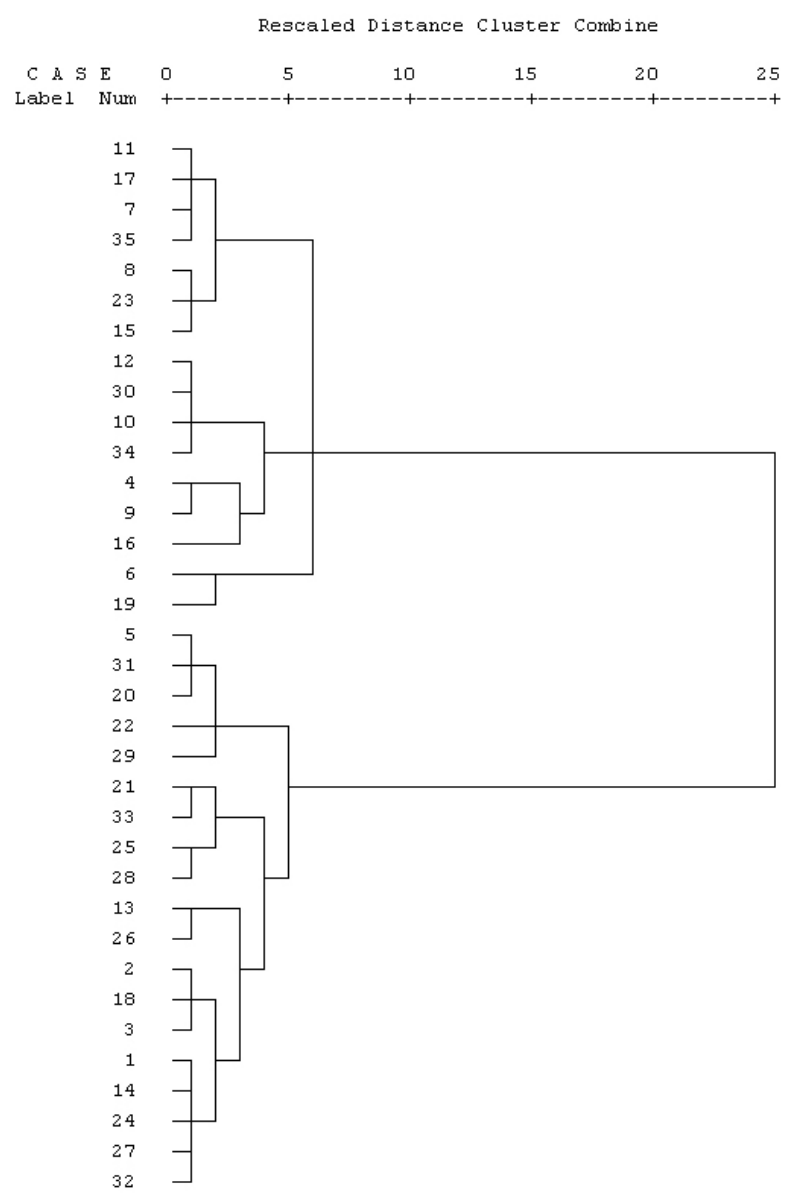

Fig. 1. Dendrogram using Ward Method

Table 2. Mean Values of Clusters

\begin{tabular}{|c|c|c|c|c|}
\hline \multirow[b]{2}{*}{ Variable } & \multirow[b]{2}{*}{ Item } & \multicolumn{2}{|c|}{ Mean Value } & \multirow[b]{2}{*}{ Significance } \\
\hline & & $\begin{array}{c}\text { Cluster } \\
1\end{array}$ & $\begin{array}{c}\text { Cluster } \\
2\end{array}$ & \\
\hline v18 & How important is SCM in your company? & 4.16 & 4.62 & 0.058 \\
\hline v19 & How successful is SCM in your company? & 3.21 & 3.50 & 0.354 \\
\hline v20 & $\begin{array}{l}\text { How much does your company trust its SCM } \\
\text { cooperation partners? }\end{array}$ & 3.58 & 4.19 & 0.039 \\
\hline v21 & $\begin{array}{l}\text { How good is the communication between your } \\
\text { company and its SCM cooperation partners? }\end{array}$ & 3.84 & 3.81 & 0.913 \\
\hline v22 & $\begin{array}{l}\text { To what extent does your company use SCM } \\
\text { Software? }\end{array}$ & 1.63 & 4.56 & 0.000 \\
\hline v23 & $\begin{array}{l}\text { How fast can your company react to change } \\
\text { requests of cooperation partners? }\end{array}$ & 3.68 & 4.00 & 0.393 \\
\hline
\end{tabular}


These clusters of firms separated by their differing degrees of SCM implementation should, as predicted by transaction cost economics, also differ with respect to the transaction dimensions of asset specificity, uncertainty and frequency as formulated in the propositions in section 3 . Before being able to test these, the variables measuring the transaction dimensions need to be condensed to single factors. This is done in the following subsection.

\subsubsection{Transaction Dimensions}

To measure the three factors of Asset Specificity, Uncertainty, and Frequency the authors based their questionnaire on some validated previous studies which deal with the indirect measurement of transaction costs via transaction dimensions as well (see [5], [6], [7], and [18]).

To answer the question of whether the correlations among the variables are consistent with a hypothesized factor structure, different confirmatory factor analyses were conducted in a stepwise process. During this process, items with small factor loadings were eliminated as well as items with insufficient communalities or substantial loadings from more than one factor. The results obtained after this procedure are presented in Table 3. It is shown that the factors Asset Specificity as well as Uncertainty only consist of three variables whereas four variables were eliminated during the refinement process. Apparently, in our study these items are not appropriate to measure these two postulated factors with regard to the SCM problem. Concerning the variables v38 and v39 one factor (Frequency) was identified, explaining about $70 \%$ of item variance.

Table 3. Confirmatory Factor Analyses: Results (extracted factors, items, variables, communalities, factor loadings, item variance)

\begin{tabular}{|c|c|c|c|c|c|}
\hline Factor & Item & Variable & Comm. & Load. & Variance \\
\hline \multirow{6}{*}{ 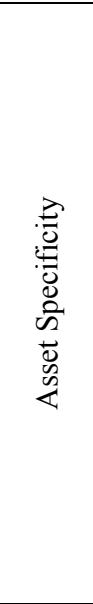 } & $\begin{array}{l}\text { How much did your company invest } \\
\text { to implement SCM? }\end{array}$ & v24 & 0.607 & 0.779 & \multirow{3}{*}{$60.748 \%$} \\
\hline & $\begin{array}{l}\text { In comparison to other departments, } \\
\text { are operating expenses relatively } \\
\text { high? }\end{array}$ & v25 & 0.572 & 0.756 & \\
\hline & $\begin{array}{l}\text { How much would the costs of } \\
\text { transacting increase without SCM? }\end{array}$ & v26 & 0.644 & 0.802 & \\
\hline & $\begin{array}{l}\text { How high would the costs incurred be } \\
\text { if a cooperation partner was lost? }\end{array}$ & v27 & $*$ & $*$ & $*$ \\
\hline & $\begin{array}{l}\text { How much time do new employees } \\
\text { need in order to be familiarized with } \\
\text { your company's SCM? }\end{array}$ & v28 & $*$ & $*$ & $*$ \\
\hline & $\begin{array}{l}\text { To what extent does your company } \\
\text { train new employees specifically in } \\
\text { SCM? }\end{array}$ & v29 & $*$ & $*$ & $*$ \\
\hline
\end{tabular}




\begin{tabular}{|c|c|c|c|c|c|}
\hline & $\begin{array}{l}\text { How much special know-how do } \\
\text { other firms need to cooperate with } \\
\text { your firm via SCM? }\end{array}$ & v30 & $*$ & $*$ & $*$ \\
\hline \multirow{7}{*}{ 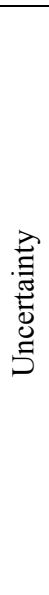 } & $\begin{array}{l}\text { How accurately can your company } \\
\text { forecast within the area of SCM? }\end{array}$ & v33 & 0.693 & 0.832 & \multirow{3}{*}{$56.968 \%$} \\
\hline & $\begin{array}{l}\text { How well can the performance of } \\
\text { cooperation partners be judged? }\end{array}$ & v34 & 0.402 & 0.634 & \\
\hline & $\begin{array}{l}\text { How well can your own company's } \\
\text { SCM performance be judged? }\end{array}$ & v35 & 0.615 & 0.784 & \\
\hline & $\begin{array}{l}\text { How well can deviant behavior be } \\
\text { controlled and sanctioned? }\end{array}$ & v36 & $*$ & $*$ & $*$ \\
\hline & $\begin{array}{l}\text { How much does the size of } \\
\text { transactions differ within SCM? }\end{array}$ & v31 & $*$ & $*$ & $*$ \\
\hline & $\begin{array}{l}\text { How much does the interval between } \\
\text { transactions differ within SCM? }\end{array}$ & v32 & $*$ & $*$ & $*$ \\
\hline & $\begin{array}{l}\text { How often does actual performance } \\
\text { differ from agreed performance? }\end{array}$ & v37 & $*$ & $*$ & $*$ \\
\hline \multirow{2}{*}{ 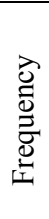 } & $\begin{array}{l}\text { How frequently are identical or } \\
\text { similar transactions carried out in } \\
\text { SCM? }\end{array}$ & v38 & 0.693 & 0.833 & \multirow[b]{2}{*}{$69.343 \%$} \\
\hline & $\begin{array}{l}\text { How important are the transactions } \\
\text { conducted with SCM cooperation } \\
\text { partners? }\end{array}$ & v39 & 0.693 & 0.833 & \\
\hline
\end{tabular}

*... stepwise excluded variables.

\section{Results}

In order to test the propositions 3 and 4, regression analyses were conducted, the results of which are presented in tables 4 and 5 . According to the assumption that there is also a positive correlation between the two independent variables Uncertainty and Frequency (see proposition 4) we calculated two regression analyses with the dependent variable Asset Specificity. When multicollinearity, a measure to which extent a variable can be explained by the other variables in the analysis, is present, none of the regression coefficients may be significant because of the large size of the standard error. Hence, it is advisable to compute two separate analyses instead of a multiple regression analysis.

Concerning the effect of Uncertainty on Asset Specificity, a positive influence is assumed in proposition 3. As shown in table 5, the results of the regression analysis emphasize a significant positive impact. The standardized regression coefficient (0.469) confirms this assumption and infers a close connection between these two variables. The coefficient of determination, R-square $(0.220)$ indicates that the independent variable Uncertainty explains over twenty percent of the total variance. 
The assumption that a positive correlation exists between Uncertainty and Asset Specificity can therefore be accepted.

Table 4. Regression Analysis Uncertainty $\rightarrow$ Asset Specificity

\begin{tabular}{|c|c|c|c|}
\hline $\begin{array}{c}\text { Regression } \\
\text { Analysis }\end{array}$ & \multicolumn{3}{|c|}{ Asset Specificity } \\
\hline & Regress. & $\begin{array}{c}\text { Stand. } \\
\text { Regress. } \\
\text { Coeff. } \beta\end{array}$ & Prob. $\mathrm{p}$ \\
\hline $\mathrm{N}=35)$ & Coeff. B & 0.469 & 0.004 \\
\hline Uncertainty & 0.469 & $\mathrm{r}^{2}=0.220$ \\
\hline R-Square & \multicolumn{3}{|c|}{$\mathrm{df}=34$} \\
\hline $\begin{array}{c}\text { Analysis of } \\
\text { Variance } \\
\text { (ANOVA) }\end{array}$ & \multicolumn{3}{|c|}{$\mathrm{F}=9.316$} \\
$\mathrm{p}=0.004$ \\
\hline
\end{tabular}

To test the proposition 4, which assumes that a positive correlation between Frequency and Asset Specificity as well as Uncertainty exists, two further regression analyses were conducted with Frequency as the independent, and Asset Specificity and Uncertainty as the dependent variables. The results in table 5 show a highly significant (0.000) positive regression effect $(0.569)$ of Frequency on Asset Specificity. The indicator R-Square (0.324) specifies the defined variance of Asset Specificity and show that one third of the overall variance of Asset Specificity is explained. The results of the ANOVA show the validity of the regression analysis for the population and test the fit of the regression function to the empirical data. The results obtained support the predicted positive impact of Frequency to Asset Specificity, proposition 4 is partially confirmed. For the relationship between Frequency and Uncertainty, a significant positive impact may also be asserted (see Table 5). The standardized regression coefficients point to a strong positive correlation between the dependent variable and the independent variable (B(Frequency) $=0.424)$. The coefficient of determination shows that the variable is able to explain approximately twenty percent of the variance. According to this result, Frequency has an important impact on the dependent variable. To that effect, proposition 4 can now be confirmed.

Finally, we tested propositions 1,2 , and 5. As the clustering yielded two dissimilar groups based on SCM implementation, the propositions predict different degrees of asset specificity, uncertainty and frequency for the two clusters. As cluster 2 firms are characterized by a higher degree of SCM implementation, the transaction dimensions should be higher as well. Table 6 shows that this is the case as all means are significantly higher ( $95 \%$ confidence) for cluster 2 than for cluster 1 , suggesting that the three factors proposed by Williamson do at least correlate with organizational choices and their specific design (i.e. the degree of implementation). 
Table 5. Regression Analyses Frequency $\rightarrow$ Asset Specificity, Uncertainty

\begin{tabular}{|c|c|c|c|}
\hline $\begin{array}{c}\text { Regression } \\
\text { Analyses }\end{array}$ & \multicolumn{3}{|c|}{ Asset Specificity } \\
\hline$(\mathrm{N}=35)$ & $\begin{array}{l}\text { Regress. } \\
\text { Coeff. B } \\
\end{array}$ & $\begin{array}{c}\text { Stand. } \\
\text { Regress. } \\
\text { Coeff. } \beta\end{array}$ & Prob. $\mathrm{p}$ \\
\hline Frequency & 0.569 & 0.569 & 0.000 \\
\hline R-Square & \multicolumn{3}{|c|}{$r^{2}=0.324$} \\
\hline $\begin{array}{l}\text { Analysis of } \\
\text { Variance } \\
\text { (ANOVA) }\end{array}$ & \multicolumn{3}{|c|}{$\begin{array}{c}\mathrm{df}=34 \\
\mathrm{~F}=15.797 \\
\mathrm{p}=0.000\end{array}$} \\
\hline & \multicolumn{3}{|c|}{ Uncertainty } \\
\hline$(\mathrm{N}=35)$ & $\begin{array}{l}\text { Regress. } \\
\text { Coeff. B } \\
\end{array}$ & $\begin{array}{c}\text { Stand. } \\
\text { Regress. } \\
\text { Coeff. } \beta\end{array}$ & Prob. $\mathrm{p}$ \\
\hline Frequency & 0.424 & 0.424 & 0.011 \\
\hline R-Square & \multicolumn{3}{|c|}{$\mathrm{r}^{2}=0.180$} \\
\hline $\begin{array}{l}\text { Analysis of } \\
\text { Variance } \\
\text { (ANOVA) }\end{array}$ & \multicolumn{3}{|c|}{$\begin{array}{c}\mathrm{df}=34 \\
\mathrm{~F}=7.241 \\
\mathrm{p}=0.011\end{array}$} \\
\hline
\end{tabular}

Table 6. Mean Values of Transaction Dimensions by Cluster

\begin{tabular}{|l|c|c|c|}
\hline $\begin{array}{l}\text { Transaction } \\
\text { Dimension }\end{array}$ & $\begin{array}{c}\text { Cluster 1 } \\
\text { (low SCM) }\end{array}$ & $\begin{array}{c}\text { Cluster 2 } \\
\text { (high SCM) }\end{array}$ & Significance \\
\hline $\begin{array}{l}\text { Asset } \\
\text { Specificity }\end{array}$ & -0.312 & 0.371 & 0.042 \\
\hline Uncertainty & -0.371 & 0.440 & 0.015 \\
\hline Frequency & -0.346 & 0.411 & 0.023 \\
\hline
\end{tabular}
*results are re-scaled following a standard normal distribution $(\mu=0, \sigma=1)$

\section{Discussion}

It has been argued that SCM can be considered as another hybrid form in a transaction costs framework. Companies which actively manage their supply and demand relations through systemic and strategic SCM cooperation are more closely entwined with their partners than parties solely completing singular spot market exchanges. With this understanding, however, the central question of this study arose, whether the degree of SCM implementation, i.e. the strength of cooperative efforts implies greater values for the factors causing internalization of transactions. We were able to show that this is the case for our sample. However, the data obtained did not permit 
tests for causality. Hence, further research is needed to prove or reject the hypothesis that the specific parameter values of the transaction dimensions actually cause a company's choice of a specific degree of SCM implementation.

Nevertheless, the significant differences in mean values indicate a certain correlation and may thus aid firms in decision making processes. When a company observes the need for large investments specific to introducing SCM, or observes relatively significant difficulties of monitoring performance as well as highly frequent transactions with cooperation partners, a closer form of cooperation through a more fully implemented SCM might be feasible.

However, the results need to be put into perspective. The study is assailable on numerous grounds. Not only did we have to deal with a very small sample size, but also the use of the informant technique in connection with a highly subjective and nonuniform topic proved to be quite problematic. Similar to different definitions of $\mathrm{SCM}$ in the scientific literature, managers also have different understandings of the kind of SCM done by their companies. This and the difficulties of operationalizing the different transaction dimensions specifically for different degrees of SCM implementation may be the reason why respondents did not always understand the question correctly in the first place. On a more general level, one might question whether the key informants really answered all questions objectively in representation of the firm or whether a respondent bias exists.

Furthermore, the clusters differ most significantly for the variable describing SCM Software usage. While we think that electronic connectivity is an important dimension when conducting truly cooperative SCM, other activities were much less clearly different for the two groups. Also, for some concepts central to a supply chain orientation and necessary for SCM activities no data was collected. Whether the clusters are truly dissimilar in their SCM implementation cannot be clarified beyond all doubt.

The factors which resulted from the items measuring asset specificity, uncertainty and frequency are also somewhat problematic as a number of items had to be excluded from the analyses due to insufficient loadings. The factors obtained are hence relatively small in dimensions and are only able to account for about 70 of the sample variance. It seems like many questions did not work well as indicators for the respective transaction dimension and the measurement of the influences on transaction costs remains problematic.

Whilst keeping in mind the study's shortfalls, the results indicate at least tentatively a certain relevance of the transaction dimensions for the degree of intensity of cooperation through supply chain management. Furthermore, it was shown that the dimensions are not independent from one another. Also, a general case for considering frequency as a factor of influence was established. Thus, whilst we know of the number of weaknesses in this study, we find the results indicative of a general support for transaction cost economics. As far as we are aware, this is the first empirical test of transaction cost theoretical predictions for the cooperation through formal SCM.

Future research should attempt to clarify the causal relationship between variables, such as: Do the dimensions of the transactions cause the choice of specific governance, as proposed by TCE, or does the governance choice bring about certain transaction dimensions, or could it even be a feedback loop? In addition it could be 
interesting to consider further factors influencing transaction costs, such as measurement difficulties or connectedness [24].

\section{References}

1. Masten, S. E.: Case Studies in Contracting and Organization, Oxford 1996.

2. Mentzer, J. T./DeWitt, W./Keebler, J. S./Min, S./Nix, N. W./Smith, C. D./Zacharia, Z. G.: Defining Supply Chain Management, in: Journal of Business Logistics, Vol. 22 (2001), No. 2, pp. $1-25$.

3. Williamson, O. E.: Markets and Hierarchies, New York, Free Press (1975).

4. Williamson, O. E.: The Modern Corporation: Origin, Evolution, Attributes, in: Journal of Economic Literature, Vol. 19 (1981), December, 1537-1568.

5. Maltz, A.: Private Fleet Use: A Transaction Cost Model, in: Transportation Journal, March 1993, 46-53.

6. John, G./Weitz, B. A.: Forward Integration into Distribution: An Empirical Test of Transaction Cost Analysis, in: Journal of Law, Economics, and Organization, vol. 4, no. 2, Fall 1988, 337-355.

7. Anderson, E./Schmittlein, D. C.: Integration of the Sales Force: An Empirical Examination, in: Rand Journal of Economics, Vol. 15 (1984), No. 3, 385-395.

8. Jones, T./Riley, D. W.: Using Inventory for Competitive Advantage through Supply Chain Management, in: International Journal of Physical Distribution and Materials Management, vol. 15 (1985), no. 5, 16-26.

9. Cooper, M. C./Ellram, L. M.: Characteristics of Supply Chain Management and the Implications for Purchasing and Logistics Strategy, in: The International Journal of Logistics Management, vol. 4 (1993), no. 2, 13-24.

10.Tyndall, G./Gopal, C./Partsch, W./Kamauff, J.: Supercharging Supply Chains; New Ways to Increase Value Through Global Operational Excellence, New York, John Wiley \& Sons (1998).

11.Hobbs, J. E.: A Transaction Cost Approach to Supply Chain Management, Research Paper, MCB University Press (1996).

12.Dietrich, M.: The Economics of Quasi-Integration, in: Review of Political Economy, vol. 6 (1994), issue 1, 1-18.

13.Monteverde, K./Teece, D. J.: Appropriable Rents and Quasi-Vertical Integration, in: Journal of Law \& Economics, vol. 25 (1982), issue 2, 321-328.

14.Williamson, O. E.: Comparative Economic Organization: The Analysis of Discrete Structural Alternatives, in: Administrative Science Quarterly, vol. 36 (1991), 269-296.

15.Yvrande-Billon, A./Saussier, S.: Do Organization Choices Matter? Assessing the Importance of Governance through Performance Comparisons, in: James, H. (ed.): New Ideas in Contracting and Organizational Researches, Nova Science Publishers (2005).

16.Williamson, O. E.: Transaction-Cost Economics: The Governance of Contractual Relations, in: Journal of Law and Economics, vol. 22, October 1979, 233-262.

17.Williamson, O. E.: The Economic Institutions of Capitalism, New York, Free Press (1985).

18.Anderson, E./Weitz, B. A.: Make-or-Buy Decision: Vertical Integration and Marketing Productivity, in: Sloan Management Review, Spring 1986, 3-19.

19.Thomson, S. H./Wang, P./Leong, C. H.: Understanding Online Shopping Behaviour Using a Transaction Cost Economics Approach, in: Internet Marketing and Advertising, No. 1, Singapore (2004), 62-84.

20.SAP AG: SAP SCM 4.0, solution brief, available at: http://www.sap.com/solutions/ business-suite/scm/pdf/BWP_SCM_40.pdf (2003) [accessed: 08. March 2005]. 
21.John, G./Reve, T.: The Reliability and Validity of Key Informant Data from Dyadic Relationships in Marketing Channels, in: Journal of Marketing Research, vol. 19, November 1982, 517-524.

22.Seidler, J.: On Using Informants: A Technique for Collecting Quantitative Data and Controlling Measurement Error in Organization Analysis, in: American Sociological Review, vol. 39, no. 6, December 1974, 816-831.

23.Härdle, W./Simar, L.: Applied Multivariate Statistical Analysis, August 2004, available at: $\mathrm{http}: / /$ www.quantlet.com/mdstat/scripts/mva/htmlbook/ [accessed 24. May 2005].

24.Baker, G. P./Hubbard, T. N.: Contractibility and Asset Ownership: On-Board Computers and Governance in U.S.Trucking, NBER Working Paper, April 2003. 